\title{
Avaliação da Força Muscular de Diferentes Populações: Uma Revisão de Literatura
} Assessment of Muscular Strenght in Different Populations: A Literature Review

\author{
KARINE JOSIBEL VELASQUES STOELBEN ${ }^{1}$ \\ ESTELE CAROLINE WELTER MEEREIS² \\ JULIANA CORREAA SOARES ${ }^{3}$ \\ CARLOS BOLLI MOTA 4
}

\section{RESUMO}

Introdução: A força muscular (FM) é a capacidade do sistema músculo esquelético produzir tensão e torque. Essa é essencial em tarefas de vida diária e em atividades desportivas. A FM é utilizada para identificar indivíduos que possam estar em grupo de risco para lesões musculoesqueléticas, além de avaliar a aptidão física para desportos, o que torna sua mensuração de grande importância. Objetivo: Verificar os métodos utilizados para avaliação quantitativa da FM. Material e Métodos: Foi realizada uma pesquisa bibliográfica na base eletrônica de dados Scielo publicados entre 2007 e 2011. Os descritores utilizados para a busca foram "muscle strength" e "força muscular", foram incluídos artigos originais nos idiomas português ou inglês, que avaliassem a força muscular de membros inferiores (MMII) e superiores (MMSS) de forma quantitativa. No total, 37 artigos foram analisados. Resultados: Foi encontrada diversidade entre os estudos analisados na escolha do método de avaliação da FM. Foi verificado que o método mais utilizado para avaliação da FM foi o dinamômetro, seguido pelo teste de 1 repetição máxima (RM) e pelo teste de 10RM. Conclusão: Os métodos mais utilizados para avaliação quantitativa da FM foram o dinamômetro isocinético e teste de 1 RM, porém ainda não foi possível observar um método padrão para avaliação da FM.

\section{DESCRITORES}

Força Muscular. Biomecânica. Fisioterapia. Dinamômetro de Força Muscular

\begin{abstract}
Introduction: Muscle strength (MS) is the system's ability to produce skeletal muscle tension and torque. This is essential for daily living tasks and sporting activities. MS values are used to identify individuals at risk for musculoskeletal injuries and can also serve to evaluate physical fitness for sports practice, which makes it an important measure. Objective: To investigate the methods used for quantitative assessment of MS. Material and Methods: we performed bibliographic searches in the electronic database Scielo of articles published between 2007 and 2011. The descriptors "Muscle strength" and "força muscular" were used in the searches of originals articles in Portuguese and English investigating quantitative MS of lower and upper limbs. A total of 37 articles were analyzed. Results: Among the studies analyzed, there was a heterogeneity regarding the MS procedure. The most commonly used MS assessment method was the dynamometer, followed by the test of 1 maximum repetition (MR) and 10 MR tests. Conclusion: The mostly used methods for MS quantitative assessment was the dynamometer and 1 MR test. However, it was not possible to establish a standard method to assess MS.
\end{abstract}

\section{DESCRIPTORS}

Muscle Strength, Biomechanics, Physical Therapy Specialty, Muscle Strength Dynamometer.

1 Graduanda em Fisioterapia na Universidade Federal de Santa Maria (UFSM), Rio Grande do Sul, Brasil.

2 Fisioterapeuta, Doutoranda em Ciência do Movimento Humano pela Universidade Federal do Rio Grande do Sul. Professora Substituta do Departamento de Fisioterapia e Reabilitação da Universidade Federal de Santa Maria (UFSM), Rio Grande do Sul, Brasil.

3 Fisioterapeuta, Mestre em Distúrbios da Comunicação Humana pela Universidade Federal de Santa Maria (UFSM), Rio Grande do Sul, Brasil.

4 Professor Adjunto da Universidade Federal de Santa Maria (UFSM), Rio Grande do Sul, Brasil 
$\mathrm{F}$ rça muscular (FM) pode ser definida como a capacidade do sistema músculo esquelético produzir tensão e torque ${ }^{1}$ e está relacionada com a aptidão física vinculada à saúde, além de ter papel relevante para o desempenho físico em diversas atividades de vida diária ${ }^{2}$ e/ou esportivas ${ }^{3,4}$. A capacidade de produzir força pode ser influenciada por diversos fatores, dentre eles, detacam-se a idade ${ }^{5}$, o treinamento muscular 2,6 , as patologias ${ }^{2,7,8}$ e as intervenções cirúrgicas ${ }^{9}$.

FM é uma variável comprovadamente importante de ser avaliada não somente para obter bom desempenho na prática de esportes, como também para identificar indivíduos que possam estar em um grupo de risco para lesões musculoesqueléticas ${ }^{3}$. Além de auxiliar no reconhecimento de doenças que afetam esta variável, e, até mesmo, para verificar o impacto de um programa de treinamento ou avaliar a capacidade de gerar força de uma população especíûca².

Portanto, a avaliação de FM torna-se um elemento importante que auxilia na identificação de grupos de risco para lesões ${ }^{3}$, no aperfeiçoamento do desempenho de atletas $3,4,10,11$, na identificação do declínio da FM em idosos ${ }^{5,7,12-16}$, na evolução de doenças que diminuem a capacidade de gerar força ${ }^{2}$ e na verificação da efetividade e os efeitos de treinamentos e intervenções que auxiliam no desempenho da $\mathrm{FM}^{7,10}$, $15,17-26$

Devido à ausência de padronização de um método de avaliação de FM, a presente pesquisa se propõe a verificar os métodos utilizados em estudos que realizaram esta avaliação em diferentes populações.

\section{METODOLOGIA}

A pesquisa foi conduzida através de uma revisão sistemática da literatura, de estudos indexados no período de 2007 a 2011 na base eletrônica de dados Scielo. Os termos utilizados para a busca dos artigos, de acordo com os Descritores em Ciências da Saúde (DeCS) foram: muscle strength e força muscular. Também foi realizada uma busca nas referências dos artigos encontrados para suprir informações relacionadas ao tema.

Os critérios de inclusão foram: artigos originais de pesquisa publicados entre 2007 e 2011 nos idiomas português ou inglês, que avaliassem a força muscular de membros inferiores (MMII) e superiores (MMSS) de forma quantitativa. Diante destes critérios foram selecionados 37 artigos para análise conforme demonstrado na Figura 1.

\section{RESULTADOS E DISCUSSÃO}

A síntese dos artigos está ilustrada no Quadro 1, no qual pode ser observado que foram analisadas diversas variáveis referentes à FM com diferentes temáticas.

A FM vem sendo investigada em diferentes tipos de populações e 21 estudos tiveram sua pesquisa voltada para a população de indivíduos saudáveis de diferentes idades. Alguns com grupo de estudo formado por jovens do sexo feminino ${ }^{1,21,23-27}$, jovens do sexo masculino ${ }^{19,28,29,30}$, e outros por indivíduos idosos de ambos os $\operatorname{sexos}^{5,7,12-16,20,31,32}$. Já outros estudos foram voltados para a população de indivíduos com patologias $^{2,6,8,33,34,35}$ e em pós-operatório ${ }^{9,36}$.

Entender as relações entre as variáveis fisiológicas e biomecânicas em um esporte ajuda a alcançar o máximo desempenho dos atletas. Em virtude disso, cinco estudos avaliaram a FM de atletas para verificar efeitos de treinamentos ${ }^{10}$, comparar respostas fisiológicas e variáveis biomecânicas ${ }^{4}$, desempenho da musculatura $^{11}$, comparar efeitos de treino de força e respectivo destreino ${ }^{22}$ e descrever valores de força em diferentes articulações ${ }^{3}$.

Foi observado que os artigos apresentaram disparidade quanto ao método de avaliação de FM, ao membro e músculos avaliados, e também no momento e na quantidade de avaliações.

Dentre os estudos selecionados para a presente revisão, em 18 estudos os pesquisadores avaliaram MMII, seis MMSS e catorze ambos os membros. Já em relação aos métodos utilizados, o mais recorrente foi dinamômeto (24 estudos), mas oito usaram o teste de uma repetição máxima (1RM) e quatro (4) o teste de dez repetições máximas (10RM).

Nas pesquisas que avaliaram MMII, foi utilizado dinamômetro isocinético, dinamômetro analógico, dinamômetro isométrico conectado a um transdutor de força e a um polígrafo digital e teste de 1RM. Já os que avaliaram MMSS utilizaram dinamômetro isocinético, dinamômetro eletrônico, dinamômetro hidráulico, dinamômetro de pinçar e teste de 10RM. O Quadro 2 abaixo, ilustra os músculos e membros que foram avaliados com os respectivos métodos utilizados.

Nos estudos que abordaram avaliação de MMSS e MMII, foram utilizados miômetro ${ }^{7}$, dinamômetro eletrônico ${ }^{10}$, transdutor de força com célula de carga ${ }^{4}$, dinamômetro isocinético ${ }^{30}$, teste de $1 \mathrm{RM}^{22,25,26}$ e teste de $10 \mathrm{RM}^{18,27,28}$. 


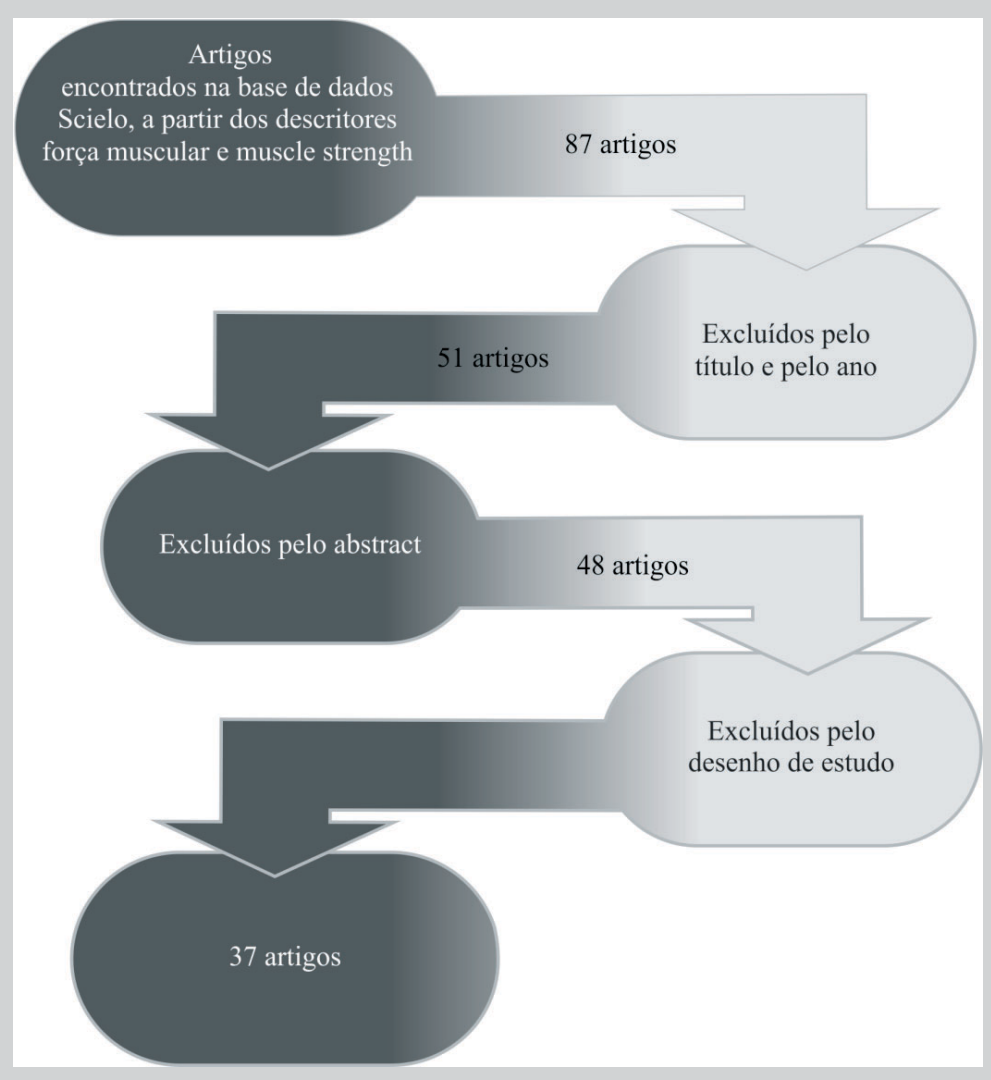

Figura 1. Seleção dos artigos

Quanto a frequência de avaliações, uma única avaliação foi a mais recorrente $e^{2,3,4,6,8,9,11-14,16,28,30-38}$. Outros estudos abordaram avaliações pré e pós-intervenção, sendo estas treinamento de força $a^{7,10,17,20,25,26}$; eletroestimulação $^{24}$, suplementação ${ }^{23}$ e alongamento ${ }^{1,29}$.

Estudo ${ }^{19}$ que buscou verificar os efeitos de um treinamento isocinético de curta duração no desempenho muscular em indivíduos jovens, avaliou a força muscular de forma diferente. Para tal, realizaram quatro testes isocinéticos para as medidas de força, potência e trabalho, permeados por três sessões de treinamento divididas ao longo dos cinco dias de duração do estudo.

Outro estudo ${ }^{27}$ no qual foi realizada a avaliação da FM de outra maneira verificou o efeito das diferentes fases do ciclo menstrual (CM) no desempenho da FM em exercícios resistidos. O efeito das oscilações hormonais decorrentes do CM sobre o desempenho físico vem sendo bastante abordado, no entanto a literatura apresenta resultados controversos. Neste artigo, os autores avaliaram a FM em cada fase do CM com o teste de 10 RM e concluíram que as fases deste não influenciaram o desempenho muscular nos exercícios resistidos, sejam eles uni ou multiarticulares, para grandes ou pequenos grupamentos musculares ou em diferentes segmentos corporais.

Pode-se identificar a frequência dos diferentes temas relacionados à FM investigados nos estudos selecionados para a presente revisão, conforme a figura 2.

Pode ser observado na Figura 2, que o tema mais frequentemente relacionado a avaliação muscular nos estudos foram a resposta fisiológica e/ou capacidade funcional. Logo, abre caminho a novas pesquisas relacionando FM com os temas menos abordados para enriquecer a literatura com informações novas. 


\begin{tabular}{|c|c|c|c|c|}
\hline \multicolumn{5}{|c|}{ Quadro1. Síntese dos artiqos encontrados na base eletrônica de dados Scielo entre 2007 e 2011.} \\
\hline Artiqo & $\mathbf{N}$ & Variáveis analisadas & Tema abordado & Conclusão \\
\hline $\begin{array}{l}\text { ALBUQUERQ } \\
\text { UE et al. }{ }^{1}\end{array}$ & 16 & $\begin{array}{l}\text { Pico de torque } \\
\text { concêntrico, pico de torque } \\
\text { excêntrico e trabalho total. }\end{array}$ & $\begin{array}{l}\text { Aquecimento } X \text { força } \\
\text { muscular }\end{array}$ & $\begin{array}{c}\text { As diversas técnicas realizadas } \\
\text { previamente ao exercício resistido não } \\
\text { produziram alteração do desempenho de } \\
\text { forca muscular. }\end{array}$ \\
\hline $\begin{array}{l}\text { ALMEIDA et } \\
\text { al. }{ }^{9}\end{array}$ & 61 & $\begin{array}{l}\text { Sexo, idade, média da } \\
\text { força muscular. }\end{array}$ & $\begin{array}{c}\text { Força muscular } \mathrm{X} \\
\text { tenotomia astroscópica }\end{array}$ & $\begin{array}{l}\text { Os pacientes submetidos à tenotomia } \\
\text { artroscópica do cabo longo do bíceps } \\
\text { apresentam significativo déficit da força de } \\
\text { flexão do cotovelo. }\end{array}$ \\
\hline $\begin{array}{l}\text { BAPTISTA et } \\
\text { al. }{ }^{4}\end{array}$ & 15 & $\begin{array}{c}\text { Consumo de oxigênio, } \\
\text { produção de dióxido de } \\
\text { carbono, ventilação, taxa } \\
\text { de troca respiratória, custo } \\
\text { metabólico, lactato, } \\
\text { frequência cardíaca, pico } \\
\text { de força, potência e } \\
\text { impulso. }\end{array}$ & $\begin{array}{l}\text { Respostas fisiológicas } \\
X \text { variáveis } \\
\text { biomecânicas }\end{array}$ & $\begin{array}{l}\text { Os remadores stroke e bow não } \\
\text { apresentaram diferenças significativas nas } \\
\text { variáveis fisiológicas e biomecânicas, com } \\
\text { exceção da potência máxima produzida. }\end{array}$ \\
\hline $\begin{array}{l}\text { BOCALINI et } \\
\text { al. }{ }^{10}\end{array}$ & 20 & $\begin{array}{l}\text { Composição corporal, } \\
\text { força muscular explosiva, } \\
\text { força máxima e testes de } \\
\text { nado (desempenho de } \\
\text { saída, resistência de } \\
\text { velocidade, velocidade } \\
\text { máxima e desempenho } \\
\text { técnico). }\end{array}$ & $\begin{array}{c}\text { Treinamento de força } \\
\text { específico } X \\
\text { desempenho }\end{array}$ & $\begin{array}{c}\text { O programa de treinamento de força } \\
\text { muscular com parachute foi eficiente para } \\
\text { aprimorar a força muscular e a velocidade } \\
\text { de nado, e houve economia de movimento } \\
\text { durante o nado. }\end{array}$ \\
\hline $\begin{array}{l}\text { CÂMARA et } \\
\text { al. }{ }^{8}\end{array}$ & 17 & $\begin{array}{l}\text { Frequência cardíaca, } \\
\text { pressão arterial, força e } \\
\text { resistência muscular. }\end{array}$ & $\begin{array}{c}\text { Resposta } \\
\text { cardiovascular X } \\
\text { Avalição muscular } \\
\text { isocinética }\end{array}$ & $\begin{array}{l}\text { Os testes isocinéticos de avaliação da } \\
\text { força e resistência musculares promovem } \\
\text { aumento da frequência cardíaca, da } \\
\text { pressão arterial sistólica e do duplo } \\
\text { produto durante sua execução. }\end{array}$ \\
\hline $\begin{array}{l}\text { CANDELORO } \\
\text { et al. }{ }^{7}\end{array}$ & 31 & $\begin{array}{l}\text { Pico de força isométrica, } \\
\text { envergadura e teste de } \\
\text { flexão. }\end{array}$ & $\begin{array}{c}\text { Hidroterapia X } \\
\text { flexibilidade e força } \\
\text { muscular }\end{array}$ & $\begin{array}{l}\text { O programa de hidroterapia proposto foi } \\
\text { eficiente para melhorar a flexibilidade e a } \\
\text { força muscular das mulheres jovens } \\
\text { idosas. }\end{array}$ \\
\hline $\begin{array}{l}\text { CARDOSO et } \\
\text { al. }^{2}\end{array}$ & 31 & $\begin{array}{l}\text { Força muscular máxima, } \\
\text { qualidade de vida e } \\
\text { distância caminhada. }\end{array}$ & $\begin{array}{l}\text { Fibromialgia } X \\
\text { qualidade de vida, } \\
\text { força e capacidade } \\
\text { funcional. }\end{array}$ & $\begin{array}{l}\text { Os resultados revelam redução da força } \\
\text { muscular em membros superiores e } \\
\text { inferiores, redução na distância percorrida } \\
\text { e também da qualidade de vida. }\end{array}$ \\
\hline $\begin{array}{l}\text { CUNHA et } \\
\text { al. }{ }^{19}\end{array}$ & 11 & Força, potência e trabalho. & $\begin{array}{c}\text { Treinamento } \\
\text { isocinético } X \\
\text { desempenho muscular }\end{array}$ & $\begin{array}{c}\text { Duas sessões de exercício resistido } \\
\text { isocinético são suficientes para induzir } \\
\text { ganhos de força. }\end{array}$ \\
\hline $\begin{array}{l}\text { DEMANGE et } \\
\text { al. }^{36}\end{array}$ & 20 & $\begin{array}{l}\text { Peso, idade, estatura, } \\
\text { índice de massa corporal, } \\
\text { torque máximo e trabalho. }\end{array}$ & $\begin{array}{c}\text { Força muscular X } \\
\text { Artroplastia total de } \\
\text { joelho }\end{array}$ & $\begin{array}{c}\text { Não há diferença na força da musculatura } \\
\text { extensora e da musculatura flexora do } \\
\text { joelho aos seis meses de cirurgia. }\end{array}$ \\
\hline DIAS et al. ${ }^{6}$ & 26 & $\begin{array}{l}\text { Limitações ortopédicas, } \\
\text { indice tornozelo-braço, } \\
\text { força máxima e histórico } \\
\text { médico (níveis de } \\
\text { atividade física, tabagismo } \\
\text { e doencas associadas). }\end{array}$ & Teste de 1RM X DAOP & $\begin{array}{c}\text { A medida acurada da força máxima é } \\
\text { obtida quando duas sessões de testes de } \\
\text { 1-RM são realizadas. }\end{array}$ \\
\hline
\end{tabular}




\begin{tabular}{|c|c|c|c|c|}
\hline $\begin{array}{l}\text { ENDLICH et } \\
\text { al. }{ }^{28}\end{array}$ & 14 & Força muscular dinâmica. & $\begin{array}{l}\text { Alongamento } \mathrm{X} \text { força } \\
\text { muscular }\end{array}$ & $\begin{array}{c}\text { Sessões de alongamentos estáticos antes } \\
\text { de atividades de força dinâmica alteraram } \\
\text { neqativamente esse desempenho. }\end{array}$ \\
\hline $\begin{array}{l}\text { ERNESTO et } \\
\text { al. }^{5}\end{array}$ & 20 & $\begin{array}{l}\text { Massa corporal, estatura, } \\
\text { composição corporal, pico } \\
\text { de torque, trabalho total e } \\
\text { índice de fadiqa. }\end{array}$ & $\begin{array}{l}\text { Intervalo de } \\
\text { recuperação X Força } \\
\text { muscular }\end{array}$ & $\begin{array}{l}\text { Os resultados mostraram que o índice de } \\
\text { fadiga exerce importante influência sobre } \\
\text { o desempenho muscular isocinético. }\end{array}$ \\
\hline $\begin{array}{l}\text { FERREIRA et } \\
\text { al. }^{11}\end{array}$ & 23 & $\begin{array}{l}\text { Pico de torque (PT), PT } \\
\text { normalizado, PT médio, } \\
\text { potência média, trabalho } \\
\text { total da repetição máxima } \\
\text { e quantidade de trabalho } \\
\text { total. }\end{array}$ & $\begin{array}{l}\text { Desempenho } \\
\text { isocinético X Membro } \\
\text { dominante e não- } \\
\text { dominante }\end{array}$ & $\begin{array}{l}\text { Apesar das diferenças entre membro } \\
\text { dominante e membro não-dominante, } \\
\text { essas diferenças não os predispõem à } \\
\text { incidência de lesões. }\end{array}$ \\
\hline $\begin{array}{l}\text { GARCIA et } \\
\text { al. } .^{12}\end{array}$ & 81 & $\begin{array}{l}\text { Força e potência muscular } \\
\text { e as medidas clínicas de } \\
\text { circunferência, mobilidade } \\
\text { funcional e nível de } \\
\text { atividade física. }\end{array}$ & $\begin{array}{l}\text { Função muscular } X \\
\text { Mobilidade funcional } X \\
\text { Nível de atividade } \\
\text { física }\end{array}$ & $\begin{array}{l}\text { Existe associação entre a função } \\
\text { muscular, FPP e velocidade de marcha } \\
\text { máxima: esses parâmetros diminuem com } \\
\text { o envelhecimento, e a FPP pode prever } \\
\text { reducão de funcão muscular em idosas. }\end{array}$ \\
\hline $\begin{array}{l}\text { GERALDES } \\
\text { et } a .^{31}\end{array}$ & 19 & $\begin{array}{l}\text { FPM, velocidade máxima } \\
\text { de caminhada, timed up \& } \\
\text { go test, colocar e retirar } \\
\text { chave de fechadura e tirar } \\
\text { e recolocar lâmpada em } \\
\text { um bocal. }\end{array}$ & $\begin{array}{l}\text { FPM X desempenho } \\
\text { funcional }\end{array}$ & $\begin{array}{l}\text { Conclui-se que a FPM pode ser uma boa } \\
\text { preditora do desempenho em tarefas } \\
\text { motoras em idosos frágeis. }\end{array}$ \\
\hline $\begin{array}{l}\text { GOMES et } \\
\text { al. }^{13}\end{array}$ & 72 & $\begin{array}{c}\text { Sexo, faixa etária, } \\
\text { alfabetização, ocorrência } \\
\text { de quedas, número de } \\
\text { doenças associadas, } \\
\text { número de medicamentos } \\
\text { em uso e visão, atividade } \\
\text { física regular, níveis de } \\
\text { desempenho físico nos } \\
\text { domínios equilíbrio, } \\
\text { marcha, força, medida de } \\
\text { independência funcional. }\end{array}$ & $\begin{array}{l}\text { Desempenho físcio e } \\
\text { número de quedas } X \\
\text { características } \\
\text { sociodemográficas, } \\
\text { físicas, clínicas e } \\
\text { funcionais }\end{array}$ & $\begin{array}{l}\text { Entre idosos que já caíram, piores níveis } \\
\text { de desempenho físico relacionam-se com } \\
\text { maior faixa etária, mais doenças e menos } \\
\text { independência funcional. }\end{array}$ \\
\hline $\begin{array}{l}\text { LOUREIRO et } \\
\text { al. }{ }^{27}\end{array}$ & 9 & Força muscular máxima. & $\begin{array}{c}\text { Ciclo menstrual } \mathrm{X} \text { força } \\
\text { muscular }\end{array}$ & $\begin{array}{l}\text { As fases do CM não influenciam o } \\
\text { desempenho da força muscular nos } \\
\text { exercícios resistidos. }\end{array}$ \\
\hline $\begin{array}{l}\text { LUSTOSA et } \\
\text { al. }^{20}\end{array}$ & 12 & Desempenho muscular. & $\begin{array}{l}\text { Alongamento estático } \\
\text { X força muscular }\end{array}$ & $\begin{array}{l}\text { O alongamento estático prévio não } \\
\text { interferiu no ganho de força muscular após } \\
\text { um programa de fortalecimento. }\end{array}$ \\
\hline $\begin{array}{l}\text { MACEDO et } \\
\text { al. }{ }^{21}\end{array}$ & 18 & $\begin{array}{l}\text { Força muscular máxima, } \\
\text { capacidade funcional, nivel } \\
\text { perceptivo de dor }\end{array}$ & $\begin{array}{l}\text { Isostretching } X \\
\text { resistência muscular }\end{array}$ & $\begin{array}{l}\text { O Isostretching mostrou-se eficiente para } \\
\text { diminuir a incapacidade e a dor, bem } \\
\text { como para o aumento da resistência } \\
\text { muscular de pacientes com lombalqia. }\end{array}$ \\
\hline $\begin{array}{l}\text { MEDEIROS et } \\
\text { al. }^{23}\end{array}$ & 27 & $\begin{array}{l}\text { Contração voluntária } \\
\text { isométrica máxima e } \\
\text { amplitude do } \\
\text { eletromiograma. }\end{array}$ & $\begin{array}{l}\text { Suplementação de } \\
\text { creatina } X \text { força } \\
\text { muscular }\end{array}$ & $\begin{array}{l}\text { A suplementação de creatina aumenta a } \\
\text { força isométrica máxima e a amplitude do } \\
\text { EMG pode ser utilizada como indicador } \\
\text { dessas alterações de desempenho. }\end{array}$ \\
\hline $\begin{array}{l}\text { GREGO } \\
\text { NETO et al. }{ }^{29}\end{array}$ & 36 & $\begin{array}{l}\text { Amplitude de movimento } \\
\text { ativa, pico de torque, o } \\
\text { trabalho máximo e o } \\
\text { trabalho total. }\end{array}$ & $\begin{array}{l}\text { Alongamento estático } \\
\text { X força muscular }\end{array}$ & $\begin{array}{l}\text { A capacidade máxima de produção de } \\
\text { força é dependente do volume de } \\
\text { alongamento. }\end{array}$ \\
\hline $\begin{array}{l}\text { MARQUES et } \\
\text { al. }^{22}\end{array}$ & 12 & $\begin{array}{l}\text { Força explosiva, potência } \\
\text { e força dinâmica máxima. }\end{array}$ & $\begin{array}{l}\text { Treino de força } X \\
\text { Destreino } X \\
\text { Indicadores de força }\end{array}$ & $\begin{array}{l}\text { Os resultados sugerem que } 8 \text { semanas } \\
\text { de treino de força induzem modificações } \\
\text { sianificativas da força. }\end{array}$ \\
\hline
\end{tabular}




\begin{tabular}{|c|c|c|c|c|}
\hline $\begin{array}{l}\text { SILVA NETO } \\
\text { et al. }{ }^{3}\end{array}$ & 21 & Força muscular. & $\begin{array}{c}\text { Força muscular em } \\
\text { diferentes articulações }\end{array}$ & $\begin{array}{l}\text { A diferença de valores de força devem ser } \\
\text { considerados durante a avaliação de } \\
\text { atletas de futebol do sexo feminino, seja } \\
\text { para tratamento e reabilitação de lesões, } \\
\text { ou para avaliação de prevenção a } \\
\text { doenças musculoesqueléticas. }\end{array}$ \\
\hline $\begin{array}{l}\text { PEREIRA et } \\
\text { al. }{ }^{34}\end{array}$ & 12 & $\begin{array}{l}\text { Força muscular e de } \\
\text { caminhada. }\end{array}$ & $\begin{array}{c}\text { Força muscular e } \\
\text { Capacidade funcional } \\
\text { X DAOP }\end{array}$ & $\begin{array}{l}\text { O desempenho funcional em pacientes } \\
\text { com DAOP foi fortemente correlacionado } \\
\text { com força muscular, mas não com } \\
\text { desempenho funcional. }\end{array}$ \\
\hline $\begin{array}{l}\text { BORBA } \\
\text { PINHEIRO et } \\
\text { al. }{ }^{18}\end{array}$ & 16 & $\begin{array}{l}\text { DMO, força muscular, } \\
\text { equilíbrio e qualidade de } \\
\text { vida. }\end{array}$ & $\begin{array}{l}\text { Treinamento resistido } \\
\times \text { Menopausa }\end{array}$ & $\begin{array}{c}\text { A metodologia aplicada ao treino resistido } \\
\text { pode ser recomendada a mulheres } \\
\text { menopausadas com baixa DMO. }\end{array}$ \\
\hline $\begin{array}{l}\text { REBELATTO } \\
\text { et al. }{ }^{14}\end{array}$ & 61 & $\begin{array}{l}\text { FPM e questionário (a } \\
\text { eventos de queda e } \\
\text { possíveis fatores } \\
\text { determinantes). }\end{array}$ & $\begin{array}{l}\text { Características gerais, } \\
\text { fatores determinantes } \\
\text { X FPM X Quedas }\end{array}$ & $\begin{array}{c}\text { Houve alta incidência de quedas, sendo } \\
\text { que os idosos com menor força de } \\
\text { preensão manual, os mais velhos e os } \\
\text { incapazes de assistir televisão se } \\
\text { mostraram mais propensos a sofrer } \\
\text { quedas. }\end{array}$ \\
\hline $\begin{array}{l}\text { SANTOS et } \\
\text { al. } 24\end{array}$ & 20 & $\begin{array}{c}\text { Peso corporal, cirtometria, } \\
\text { ?eximetria e força } \\
\text { muscular. }\end{array}$ & $\begin{array}{l}\text { Eletroestimulação } X \\
\text { condicionamento } \\
\text { neuromuscular }\end{array}$ & $\begin{array}{l}\text { Os aparelhos de eletroestimulação são } \\
\text { menos e?cientes do que a prática de } \\
\text { exercício físico voluntário. }\end{array}$ \\
\hline SILVA et al. ${ }^{38}$ & 8 & $\begin{array}{l}\text { Número máximo de } \\
\text { repetições, percepção } \\
\text { subjetiva de esforço e } \\
\text { força muscular máxima. }\end{array}$ & $\begin{array}{l}\text { Ordem dos exercícios } \\
\text { X } \\
\text { Desempenho físico }\end{array}$ & $\begin{array}{l}\text { Conclui-se que a ordem dos exercícios } \\
\text { influenciou o número máximo de } \\
\text { repetições e a percepção de esforço ao } \\
\text { final das sequências em idosas. }\end{array}$ \\
\hline $\begin{array}{l}\text { SOUZA et } \\
\text { al. } 25\end{array}$ & 20 & $\begin{array}{l}\text { Estatura, massa corporal, } \\
\text { dobras cutâneas, } \\
\text { percentual de gordura, } \\
\text { gordura corporal absoluta, } \\
\text { massa magra, consumo } \\
\text { máximo de oxigênio, limiar } \\
\text { ventilatório, frequência } \\
\text { cardiaca e força muscular } \\
\text { máxima. }\end{array}$ & $\begin{array}{c}\text { Treinamento de } \\
\text { resistêntica de força } X \\
\text { Capacidade } \\
\text { cardiopulmonar }\end{array}$ & $\begin{array}{l}\text { Conclui-se que o treinamento de } \\
\text { resistência de força com alto número de } \\
\text { repetições proporcionou melhora da } \\
\text { potência aeróbia das voluntárias. }\end{array}$ \\
\hline $\begin{array}{l}\text { RADAELLI et } \\
\text { al. } 30\end{array}$ & 69 & $\begin{array}{l}\text { Espessura muscular, } \\
\text { qualidade muscular e força } \\
\text { isométrica. }\end{array}$ & $\begin{array}{l}\text { Diferentes locais } \\
\text { de mensuração } X \\
\text { mensuração de } \\
\text { variáveis }\end{array}$ & $\begin{array}{c}\text { O ponto de medida exerce influência } \\
\text { significativa na espessura muscular e } \\
\text { qualidade muscular. }\end{array}$ \\
\hline $\begin{array}{l}\text { SIMÕES et } \\
\text { al. }{ }^{16}\end{array}$ & 65 & $\begin{array}{l}\text { Pico de torque, potência } \\
\text { média muscular, pressão } \\
\text { inspiratória máxima, } \\
\text { pressão expiratória } \\
\text { máxima e distância } \\
\text { caminhada. }\end{array}$ & $\begin{array}{c}\text { Força muscular, TC6 } \times \\
\text { Capacidade funcional }\end{array}$ & $\begin{array}{l}\text { A associação entre força muscular } \\
\text { respiratória e de membros inferiores } \\
\text { com a distância caminhada sugere que } \\
\text { a otimização dessas funções pode } \\
\text { contribuir para manter e/ou melhorar a } \\
\text { capacidade funcional da população idosa. }\end{array}$ \\
\hline
\end{tabular}




\begin{tabular}{|c|c|c|c|c|}
\hline $\begin{array}{l}\text { SOUZA et } \\
\text { al. }^{26}\end{array}$ & 20 & $\begin{array}{l}\text { Massa corporal, estatura, } \\
\text { medidas das dobras } \\
\text { cutâneas, densidade } \\
\text { corporal, massa corporal } \\
\text { magra e força máxima } \\
\text { dinâmica. }\end{array}$ & $\begin{array}{c}\text { Força muscular } \mathrm{X} \\
\text { Treinamento de força } \\
\text { aquático }\end{array}$ & $\begin{array}{c}\text { É possível recomendar treinamentos de } \\
\text { força no meio aquático como um método } \\
\text { alternativo e eficaz para a melhora da } \\
\text { força muscular. }\end{array}$ \\
\hline AVILA et al. ${ }^{17}$ & 20 & $\begin{array}{l}\text { Torque extensor } \\
\text { isométrico e isocinético } \\
\text { concêntrico. }\end{array}$ & $\begin{array}{l}\text { EENM X Treinamento } \\
\text { isocinético }\end{array}$ & $\begin{array}{c}\text { A associação entre a EENM e o } \\
\text { treinamento voluntário isocinético } \\
\text { concêntrico não melhorou os ganhos de } \\
\text { força e de propriedades neuromusculares. }\end{array}$ \\
\hline $\begin{array}{l}\text { CARDOSO } \\
\text { SANTOS et } \\
\text { al. }^{33}\end{array}$ & 28 & $\begin{array}{l}\text { Amplitude da mobilidade } \\
\text { articular, forças de garra e } \\
\text { de pinça, excreção urinária } \\
\text { de glicosaminoglicanos, } \\
\text { atividade da arilsulfatase B } \\
\text { e distância caminhada. } \\
\end{array}$ & $\begin{array}{c}\text { Mobilidade articular, } \\
\text { força de garra e de } \\
\text { pinça } X \\
\text { mucopolissacaridose } \\
\text { tipo VI }\end{array}$ & $\begin{array}{l}\text { A restrição da flexão de ombro, sem } \\
\text { correlação com a idade, sugere que este } \\
\text { achado esteja presente precocemente na } \\
\text { mucopolissacaridose tipo VI e se constitua } \\
\text { em sinal clínico importante para suspeita } \\
\text { diagnóstica desta doença. }\end{array}$ \\
\hline $\begin{array}{l}\text { COSTA et } \\
\text { al. }^{37}\end{array}$ & 65 & $\begin{array}{l}\text { Equilíbrio estático, torque } \\
\text { e força muscular. }\end{array}$ & $\begin{array}{l}\text { Mulheres férteis X } \\
\text { Mulheres na pós- } \\
\text { menopausa }\end{array}$ & $\begin{array}{c}\text { A diminuição da força muscular após a } \\
\text { menopausa parece estar relacionada ao } \\
\text { hipoestrogenismo e que o torque dos } \\
\text { dorsi?exores de tornozelo é um fator } \\
\text { importante para a manutenção do } \\
\text { equilíbrio estático nos primeiros anos da } \\
\text { menopausa. }\end{array}$ \\
\hline $\begin{array}{l}\text { SOUZA et } \\
\text { al. }^{35}\end{array}$ & 183 & $\begin{array}{c}\text { Frequência de } \\
\text { manifestações clínicas, } \\
\text { complicações da } \\
\text { neurofibromatose tipo 1, } \\
\text { gravidade, visibilidade, } \\
\text { alterações da motricidade } \\
\text { oral e da voz e força } \\
\text { muscular. }\end{array}$ & $\begin{array}{l}\text { Neurofibromatose tipo } \\
1 \text { X Prevalência de } \\
\text { características clínicas }\end{array}$ & $\begin{array}{l}\text { O perfil clínico destes pacientes é } \\
\text { semelhante aos relatos prévios da } \\
\text { literatura. }\end{array}$ \\
\hline $\begin{array}{l}\text { OLIVEIRA et } \\
\text { al. }^{32}\end{array}$ & 57 & $\begin{array}{c}\text { Níveis de Interleucina } 6, \\
\text { força muscular isocinética, } \\
\text { capacidade funcional e } \\
\text { velocidade da marcha. }\end{array}$ & $\begin{array}{l}\text { Interleucina } 6 \times \text { força } \\
\text { muscular e capacidade } \\
\text { funcional }\end{array}$ & $\begin{array}{l}\text { A Interleucina } 6 \text { está associada com } \\
\text { redução da força muscular. }\end{array}$ \\
\hline
\end{tabular}

N: número; RM: Repetição máxima; DAOP: Doença Arterial Obstrutiva Periférica; FPP: Força de Preensão Palmar; FPM: Força de Preensão Manual: DMO: Densidade Mineral Óssea; EENM: Estimulacão Elétrica Neuromuscular 


\begin{tabular}{|c|c|c|c|}
\hline \multicolumn{4}{|c|}{$\begin{array}{l}\text { Quadro 2. Relação entre musculatura avaliada e método de avaliação nos artigos encontrados na base } \\
\text { eletrônica de dados Scielo entre } 2007 \text { e } 2011 .\end{array}$} \\
\hline & Músculos avaliados & Método & Estudos \\
\hline \multirow[t]{4}{*}{ MMSS } & \multirow[t]{2}{*}{$\begin{array}{l}\text { Músculos que } \\
\text { realizam a preensão } \\
\text { palmar }\end{array}$} & $\begin{array}{l}\text { Dinamômetro } \\
\text { hidráulico }\end{array}$ & $\begin{array}{c}\text { CARDOSO et al. }{ }^{2} \text {, GARCIA et al..12, GERALDES et } \\
\text { al..31, REBELATTO et al. }{ }^{14} \text {, CARDOSO SANTOS et } \\
\text { al. }{ }^{33}\end{array}$ \\
\hline & & $\begin{array}{c}\text { Dinamômetro } \\
\text { manual }\end{array}$ & GOMES et al. ${ }^{13}$ \\
\hline & $\begin{array}{l}\text { Músculos que } \\
\text { realizam a preensão } \\
\text { dígito-digital e dígito- } \\
\text { lateral }\end{array}$ & $\begin{array}{l}\text { Dinamômetro de } \\
\text { pinçar }\end{array}$ & CARDOSO et al. ${ }^{2}$, CARDOSO SANTOS et al..$^{33}$ \\
\hline & Flexores do cotovelo & $\begin{array}{l}\text { Dinamômetro } \\
\text { isocinético }\end{array}$ & ALMEIDA et al. ${ }^{9}$ \\
\hline \multirow[t]{12}{*}{ MMII } & Extensores de joelho & $\begin{array}{l}\text { Dinamômetro } \\
\text { Isocinético }\end{array}$ & 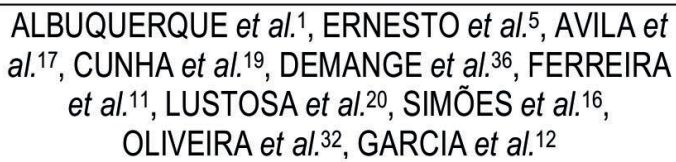 \\
\hline & & Teste de 1RM & PEREIRA et al..34, DIAS et al..6. CARDOSO et al. ${ }^{2}$ \\
\hline & \multirow[t]{2}{*}{ Flexores de joelho } & $\begin{array}{l}\text { Dinamômetro } \\
\text { Isocinético }\end{array}$ & $\begin{array}{c}\text { CUNHA et al.19, DEMANGE et al. }{ }^{36} \text {, FERREIRA et } \\
\text { al..11, LUSTOSA et al..20, SIMÕES et all.16, OLIVEIRA } \\
\text { et al..32, GARCIA et al. }{ }^{12}\end{array}$ \\
\hline & & Teste de 1RM & CARDOSO et al. ${ }^{2}$ \\
\hline & $\begin{array}{c}\text { Flexores e } \\
\text { extensores do quadril }\end{array}$ & $\begin{array}{l}\text { Dinamômetro } \\
\text { Isocinético }\end{array}$ & GARCIA et al. ${ }^{12}$ \\
\hline & Flexores plantares & $\begin{array}{l}\text { Dinamômetro } \\
\text { Isocinético }\end{array}$ & GARCIA et al. ${ }^{12}$ \\
\hline & $\begin{array}{l}\text { Dorsiflexores do } \\
\text { tornozelo }\end{array}$ & $\begin{array}{l}\text { Dinamômetro } \\
\text { Isocinético }\end{array}$ & GARCIA et al. ${ }^{12}$ \\
\hline & Isquiotibiais & $\begin{array}{l}\text { Dinamômetro } \\
\text { Isocinético }\end{array}$ & GREGO NETO et al.29 \\
\hline & \multirow[t]{3}{*}{ Quadríceps } & $\begin{array}{l}\text { Dinamômetro } \\
\text { analóaico }\end{array}$ & SANTOS et al. ${ }^{24}$ \\
\hline & & $\begin{array}{c}\text { Dinamômetro } \\
\text { isométrico } \\
\text { conectado a um } \\
\text { transdutor de força e } \\
\text { a um polígrafo } \\
\text { digital }\end{array}$ & MEDEIROS et al.23 \\
\hline & & Teste de 1 RM & COSTA et al. ${ }^{37}$ \\
\hline & Glúteo Máximo & Teste de 1 RM & MACEDO et al..21 \\
\hline
\end{tabular}

MMSS: Membros Superiores, MMII: Membros Inferiores, RM: Repetição Máxima. 


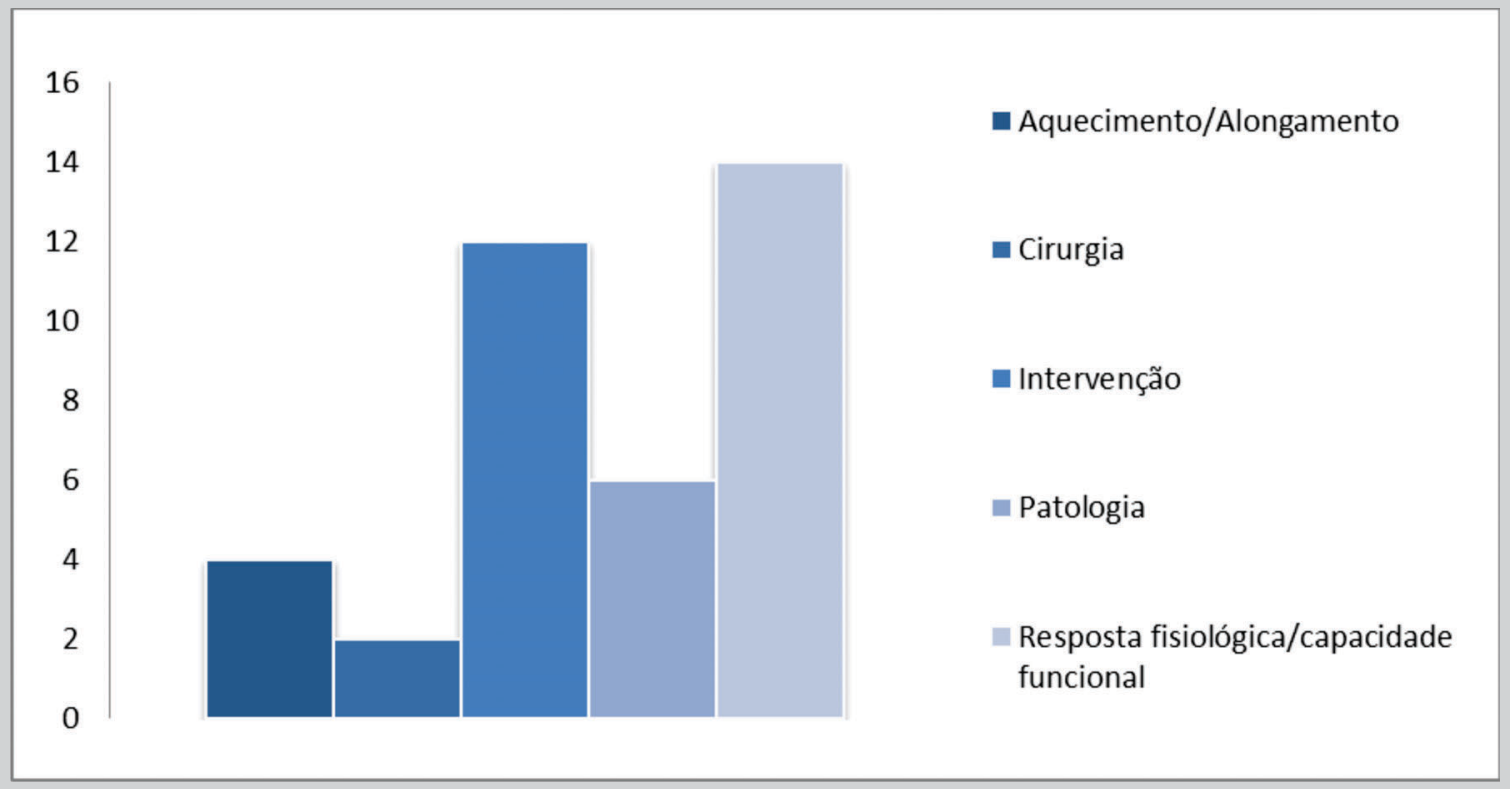

Figura 1. Quantidade de estudos que relacionaram temas com a força muscular na base eletrônica de dados Scielo entre 2007 e 2011

\section{CONCLUSÃO}

Diante dessa pesquisa foi possível observar que os métodos mais utilizados pelos pesquisadores foram: o dinamômetro isocinético e teste de $1 \mathrm{RM}$. Os trabalhos científicos realizados com avaliação de força muscular não utilizaram método padronizado.

\section{REFERÊNCIAS}

1. Albuquerque CV, Maschio JP, Gruber CR, Souza RM, Hernandez S. Efeito agudo de diferentes formas de aquecimento sobre a força muscular. Fisioter mov 2011;24(2):221-9.

2. Cardoso FS, Curtolo M, Natour J, Lombardi-Júnior I. Avaliação da qualidade de vida, força muscular e capacidade funcional em mulheres com fibromialgia. Rev Bras Reumatol 2011;51(4):338-50.

3. Silva-Neto M, Simões R, Grangeiro-Neto JA, Cardone CP. Avaliação isocinética da força muscular em atletas profissionais de futebol feminino. Rev Bras Med Esporte 2010;16(1):33-5.

4. Baptista RR, Cunha GS, Oliveira AR. Aspectos Fisiológicos e Biomecânicos da Produção de Força Podem ser Usados no Controle do Treinamento de Remadores de Elite. Rev Bras Med Esporte 2008;14(5):427-30.

5. Ernesto C, Bottaro M, Silva FM, Sales MPM, Celes RS, Oliveira RJ. Efeitos de diferentes intervalos de recuperação no desempenho muscular isocinético em idosos. Rev Bras Fisioter 2009;13(1):65-72.

6. Dias RMR, Cucato GG, Câmara LC, Wolosker N Reprodutibilidade do teste de 1-RM em indivíduos com Doença Arterial Obstrutiva Periférica. Rev Bras Med Esporte 2010;16(3):201-4.

7. Candeloro JM, Caromano FA. Efeito de um Programa de Hidroterapia na Flexibilidade e na Força Muscular de Idosas. Rev Bras Fisioter 2007;11(4):303-9.

8. Câmara LC, Ritti-Dias RM, Forjaz CLM, Greve JM, Santarém JM, Jacob-Filho W, et al. Respostas Cardiovasculares durante Avaliação Muscular Isocinética em Claudicantes. Arq Bras Cardiol 2010;95(5):571-6.

9. Almeida A, Roveda G, Valin MR, Almeida, NC. Avaliação da força de flexão do cotovelo após a tenotomia artroscópica do cabo longo do bíceps. Rev Bras Ortop 2007;42(11/12):367-72.

10. Bocalini DS, Rica RL, Triviño RN, Serra AJ. Efeitos do Treinamento de Força Específico no Desempenho de Nadadores Velocistas Treinados com Parachute. Rev Bras Ciênc Esporte 2010;32(1):217-27. 
11. Ferreira AP, Gomes AS, Ferreira CES, Arruda M, França NM. Avaliação do desempenho isocinético da musculatura extensora e flexora do joelho de atletas de futsal em membro dominante e não dominante. Rev Bras Cienc Esporte 2010;32(1):229-43.

12. Garcia PA, Dias JMD, Dias RC, Santos P, Zampa CC. Estudo da relação entre função muscular, mobilidade funcional e nível de atividade física em idosos comunitários. Rev Bras Fisioter 2011;15(1):15-22.

13. Gomes GAO, Cintra FA, Diogo MJD, Neri AL, Guariento ME, Sousa MLR. Comparação entre idosos que sofreram quedas segundo desempenho físico e número de ocorrências. Rev Bras Fisioter 2009;13(5):430-7.

14. Rebelatto JR, Castro AP, Chan A. Quedas em idosos institucionalizados: características gerais, fatores determinantes e relações com a força de preensão manual. Acta Ortop Bras 2007;15(3):151-4.

15. Rizzi PRS, Leal RM, Vendrusculo AP. Efeito da hidrocinesioterapia na força muscular e na flexibilidade em idosas sedentárias. Fisioter Mov 2010;23(4):535-43.

16. Simões LA, Dias JMD, Marinho KC, Pinto CLLR, Britto RR. Relação da função muscular respiratória e de membros inferiores de idosos comunitários com a capacidade funcional avaliada por teste de caminhada. Rev Bras Fisioter 2010;14(1):24-30.

17. Avila MA, Brasileiro JS, SalviniTF. Electrical stimulation and isokinetic training effects on strength and neuromuscular properties of healthy young adults. Rev Bras Fisioter 2008; 12(6):435-40.

18. Borba-Pinheiro CJ, Carvalho MCGA, Silva NSL, Bezerra JCP, Drigo AJ, Dantas EHM. Efeitos do treinamento resistido sobre variáveis relacionadas com a baixa densidade óssea de mulheres menopausadas tratadas com alendronato. Rev Bras Med Esporte 2010;16(2):121-5.

19. Cunha R, Martorelli AS, Carregaro RL, Bottaro M. Treinamento isocinético de curto prazo promove aumento da força muscular em indivíduos jovens. Motriz 2011;17(1):138-44.

20. Lustosa LP, Pacheco MGM, Liu AL, Gonçalves WS, Silva JP, Pereira LSM. Impacto do alongamento estático no ganho de força muscular dos extensores de joelho em idosas da comunidade após um programa de treinamento. Rev Bras Fisioter 2010;14(6):497-502.

21. Macedo CSG, Debiagi PC, Andrade FM. Efeito do isostretching na resistência muscular de abdominais, glúteo máximo e extensores de tronco, incapacidade e dor em pacientes com lombalgia. Fisioter Mov 2010;23(1):113-20.

22. Marques MC, Casimiro FLM, Marinho DA, Costa AFMMC. Efeitos do treino e do destreino sobre indicadores de força em jovens voleibolistas: implicações da distribuição do volume. Motriz 2011;17(2):235-43.

23. Medeiros RJD, Santos AA, Ferreira ACD, Ferreira JJA, Carvalho LC, Sousa MSC. Efeitos da suplementação de creatina na força máxima e na amplitude do eletromiograma de mulheres fisicamente ativas. Rev Bras Med Esporte 2010;16(5):353-7.

24. Santos FM, Rodrigues RGS, Trindade-Filho EM. Exercício físico versus programa de exercício pela eletroestimulação com aparelhos de uso doméstico. Rev Saúde Pública 2008;42(1):117-22.

25. Souza TMF, Cesar MC, Borin JP, Gonelli PRG, Simões RA, Montebelo MIL. Efeitos do treinamento de resistência de força com alto número de repetições no consumo máximo de oxigênio e limiar ventilatório de mulheres. Rev Bras Med Esporte 2008;14(6):513-7.
26. Souza AS, Rodrigues BM, Hirshammann B, Graef FI, Tiggemann CL, Kruel LFM. Treinamento de força no meio aquático em mulheres jovens. Motriz 2010;16(3):649-57.

27. Loureiro S, Dias I, Sales D, Alessi I, Simão R, Fermino RC. Efeito das diferentes fases do ciclo menstrual no desempenho da força muscular em 10RM. Rev Bras Med Esporte 2011;17(1):22-5.

28. Endlich PW, Farina GR, Dambroz C, Gonçalves WLS, Moysés MR, Mill JG, et al. Efeitos agudos do alongamento estático no desempenho da força dinâmica em homens jovens. Rev Bras Med Esporte 2009;15(3):200-3.

29. Grego-Neto A, Manffra EF. Influência do volume de alongamento estático dos músculos isquiotibiais nas variavéis isocinéticas. Rev Bras Med Esporte 2009;15(2):104-9.

30. Radaelli R, Wilhelm-Neto EN, Marques MFB, Pinto RS Espessura e qualidade musculares medidas a partir de ultrassonografia: influência de diferentes locais de mensuração. Rev Bras Cineantropom Desempenho Hum 2011;13(2):87-93.

31. Geraldes AAR, Oliveira ARM, Albuquerque RB, Carvalho JM, Farinatti PTV. A força de preensão manual é boa preditora do desempenho funcional de idosos frágeis: um estudo correlacional múltiplo. Rev Bras Med Esporte 2008;14(1):12-6.

32. Oliveira DMG, Narciso FMS, Santos MLAS, Pereira DS, Coelho FM, Dias JMD, et al. Muscle strength but not functional capacity is associated with plasma interleukin6 levels of community-dwelling elderly women. Braz J Med Biol Res 2008;41:1148-53.

33. Cardoso-Santos A, Azevedo ACMM, Fagondes S, Burin MG, Giugliani R, Schwartz IVD. Mucopolysaccharidosis type VI (Maroteaux-Lamy syndrome): assessment of joint mobility and grip and pinch strength. J Pediatr 2008;84(2):130-5.

34. Pereira DAG, Faria BMA, Gonçalves RAM, Carvalho VBF, Prata KO, Navarro TP, et al. Relação entre força muscular e capacidade funcional em pacientes com doença arterial obstrutiva periférica: um estudo piloto. J Vasc Bras 2011;10(1): 26-30

35. Souza JF, Toledo LL, Ferreira MCM, Rodrigues LOC, Rezende NA. Neurofibromatose tipo 1: mais comum e grave do que se imagina. Rev Assoc Med Bras 2009;55(4):394-9.

36. Demange MK, Camanho GL, Pécora JR, Greve JM, Silva ALP, Reginato TJB. Avaliação isocinética em pacientes submetidos à artroplastia total de joelho. Acta Ortop Bras 2008; 17(1):22-5.

37. Costa GC, Reis JG, Rosa RC, Ferreira CHJ, Volpon JB, Abreu DCC. Static balance, quadriceps strength and ankle dorsiûexor torque in fertile and post-menopausal women. Fisioter Mov 2010;23(4):585-91.

38. Silva NSL, Monteiro WD, Farinatti PTV. Influência da ordem dos exercícios sobre o número de repetições e percepção subjetiva do esforço em mulheres jovens e idosas. Rev Bras Med Esporte 2009;15(3):219-23.

\section{Correspondência}

Karine Josibel Velasques Stoelben

Endereço: Av. Roraima, 1000, prédio 51, sala 1007

(Laboratório de Biomecânica),

Santa Maria - Rio Grande do Sul - Brasil

CEP: $97105-900$

E-mail: karinestoelben@gmail.com 